\title{
Intermolecular Hydride Transfer Reactions. VII. Isomerisation of Dihydropyran Derivatives Catalysed by Pyrylium Cations
}

\author{
EILIF TERJE ØSTENSEN and MORCOS MICHAEL MISHRIKEY*
}

Organic Chemistry Laboratories, The Norwegian Institute of Technology, University of Trondheim, N-7034 Trondheim-NTH, Norway

Isomerisation of dihydropyran derivatives in the presence of pyrylium cations has been studied. 4-Phenylflav-3-ene was quantitatively converted to 4-phenylflav-2-ene by means of 4-phenylflavylium perchlorate in boiling acetonitrile solution, suggesting greater stability of the 2-flavene isomer. Hydride transfer between the $\gamma$-positions of the 2-isomer and the flavylium cation was shown to be more favourable than hydride transfer between the $\alpha, \alpha$ - or the $\alpha, \gamma$-positions of the 3 -isomer and the same cation. Treatment of 2,6-diphenyl- and 2,4,6triphenyl-4H-pyrans with their corresponding pyrylium cations led to the formation of cinnamylideneacetophenone and 1,3,5-triphenylpent. 2,4-dienone, respectively. Transformation of the $4 H$-pyran to the $2 H$-pyran catalysed by the pyrylium cation and subsequen: valence isomerisation of the $2 H$-pyran leading to the most stable dienone isomer accounted for these products.

Formate reduction of 2,6-diphenyl- and 2,4,6-triphenylpyrylium cations led to the formation of 2,6-diphenyl-4H-pyran and 1,3,5triphenylpent-2,4-dienone, respectively.

Recently we reported ${ }^{1}$ that flavylium cations are quantitatively reduced into flavenes by means of formate anion. In this respect, 4-phenylflavylium perchlorate (1a) afforded a mixture (approximately 1:1) of 4-phenylflav-2-ene (2a) and 4-phenylflav-3-ene (3a) on treatment with sodium formate in boiling acetonitrile solution (Scheme 1A). The forma. tion of carbon dioxide from the hydride donor is assumed to make the reaction irreversible, hence the ratio between the obtained flavenes should be kinetically controlled. However, the

* Present address: Chemistry Dep., Faculty of Science, Moharrem Bey, Alexandria, Egypt.

Acta Chem. Scand. B 30 (1976) No. 7 presence of unreacted flavylium salt (1a) alongside the produced flavenes $2 a, 3 a$ gives rise to the possibility of a concurrent intermolecular hydride transfer between the flavylium cation and the flavenes. Interconversion of the flavene isomers through a common transition state should be possible by this route. This would lead to an increased yield of the thermodynamically more stable flavene. Accordingly, the observed $1: 1$ ratio between the flavenes $2 a$ and $3 a$ obtained from the formate reduction of $1 a$ may not be related to the kinetically controlled reaction only.

The present work deals with the isomerisation of dihydropyran derivatives catalysed by pyrylium cations and furthermore a comparative study of the relative stabilities of $4 H$-pyrans versus $2 H$-pyrans and their open chain dienone valence isomers has been attempted.

An equimolar mixture of 4-phenylflav-2-ene (2a) and 4-phenylflavylium perchlorate (1a) in acetonitrile solution was recovered unchanged after keeping 3 days at $20^{\circ} \mathrm{C}$. Similar result was obtained from a mixture of the 4-phenylflav-3-ene ( $3 a)$ and the flavylium salt 1a. Thus, at room temperature, isomerisation of the flavenes $2 a$ and $3 a$ seems not to be important. When a mixture of 4-phenylflav2-ene (2a) and 3-deuterio-4-phenylflavylium perchlorate (1b) was used, an equilibrium mixture consisting of 4-phenylflav-2-ene (2a), 3-deuterio-4-phenylflav-2-ene (2b), 4-phenylflavylium perchlorate $(1 a)$, and 3-deuterio-4phenylflavylium perchlorate $(1 b)$ in equimolar ratio was obtained. The same equilibrium 
A

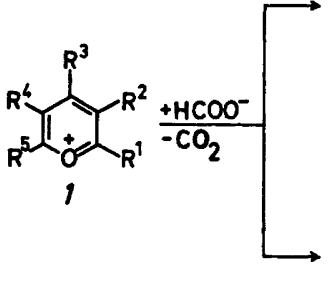<smiles>[R]C1=C([R])C([R])C([R])=C([R])C1[R]</smiles><smiles></smiles>

B<smiles>[R]C(=O)C([R])=C([R2])C([R])C([R])=O</smiles><smiles>[R]C(S)=C([R])C([R])=C([R])C([R])[R]</smiles><smiles>[R]/C=C(/[R])C([R])=C([R7])C([R])=O</smiles>

Scheme 1. Explanation of $\mathbf{R}^{1}-R^{5}$, see Table 1

mixture was formed in a reaction starting with 3-deuterio-4-phenylflav-2-ene (2b) and 4-phenylflavylium perchlorate (1a). Hence a reversible hydride transfer between the $\gamma$-positions of 4-phenylflav-2-ene and 4-phenylflavylium cation takes place at room temperature. On the other hand, 4-phenylflav-3-ene (3a) was recovered unchanged on treatment with the 3-deuterated flavylium cation $1 b$. These results suggest a more energetically favourable transition state for hydride transfer involving $\gamma, \gamma$ positions rather than $\alpha, \alpha$ or $\alpha, \gamma$ positions in the above-mentioned systems. The latter hydride transfer which could not be detected at room temperature took place at higher temperature. Thus, 4phenylflav-2-ene $(2 a)$ alongside the 4-phenylflavylium cation $(1 a)$ were quantitatively obtained from 4-phenylflav-3-ene $(3 a)$ and the cation $1 a$ in boiling acetonitrile solution. When the 3-deuterated flavylium cation $1 b$ was used in the latter reaction, the expected

Table 1. Substituents of compounds $1-6$.

\begin{tabular}{llllll}
\hline & $\mathrm{R}^{1}$ & $\mathrm{R}^{2}$ & $\mathrm{R}^{3}$ & $\mathrm{R}^{4}$ & $\mathrm{R}^{5}$ \\
\hline$a$ & $\mathrm{C}_{6} \mathrm{H}_{5}$ & $\mathrm{H}$ & $\mathrm{C}_{6} \mathrm{H}_{5}$ & \multicolumn{2}{l}{$-(\mathrm{CH}=\mathrm{CH})_{2}-$} \\
$b$ & $\mathrm{C}_{6} \mathrm{H}_{5}$ & $\mathrm{D}$ & $\mathrm{C}_{6} \mathrm{H}_{5}$ & & $\mathrm{H}$ \\
$c$ & $\mathrm{C}_{6} \mathrm{H}_{5}$ & $\mathrm{H}$ & $\mathrm{H}^{\mathrm{H}}$ & $\mathrm{C}_{6} \mathrm{H}_{5}$ \\
$d$ & $\mathrm{C}_{6} \mathrm{H}_{5}$ & $\mathrm{H}$ & $\mathrm{C}_{6} \mathrm{H}_{5}$ & $\mathrm{H}$ & $\mathrm{C}_{6} \mathrm{H}_{5}$ \\
$e$ & $\mathrm{C}_{6} \mathrm{H}_{5}$ & $\mathrm{H}$ & $\mathrm{CH}_{3}$ & $\mathrm{H}$ & $\mathrm{CH}_{3}$ \\
\hline
\end{tabular}

1:1 equilibrium mixture of deuterated and undeuterated flav-2-enes ( $2 b$ and $2 a$ ) besides the corresponding flavylium cations ( $1 b$ and 1a), was obtained. This indicates that 4-phenylflav-2-ene $(2 a)$ is thermodynamically more stable than 4-phenylflav-3-ene $(3 a)$ and that the isomerisation of $3 a$ into $2 a$ is possible under conditions similar to those used in the formate reduction of the cation $1 a$. Since the above isomerisation is undetectable at room temperature, the formate reduction of $1 a$ was repeated at $20^{\circ} \mathrm{C}$. The ratio between the produced flavenes $2 a$ and $3 a$ in the latter case was found to be the same as that obtained in boiling acetonitrile. Since the yield of the relatively unstable isomer $3 a$ was not increased, it seems likely that isomerisation of $3 a$ into $2 a$, can be neglected even when the formate reduction is carried out in boiling acetonitrile solution. Based on the roughly estimated ratio ( ${ }^{1} \mathrm{H}$ NMR) between $2 a$ and $3 a$, the rate of the hydride transfer from the formate anion to the $\alpha$ - and the $\gamma$-positions of $1 a$ seems to be approximately the same.

While the equilibrium between $2 H$-pyrans and cis-dienones has been extensively studied ${ }^{2-4}$ (Scheme 1B), little attention was given to the stabilities of these valence isomers versus the isomeric $4 H$-pyrans. In this respect it should be pointed out that for the flavenes $2 a$ and $3 a$ which are dihydropyran derivatives, the $4 H$-pyran $2 a$ being more stable than the

Acta Chem. Scand. B 30 (1976) No. 7 
$2 H$-pyran $3 a$ must also be more stable than the "dienones" which can arise through valence isomerisation of the latter. However, no change was observed in the ${ }^{1} \mathrm{H}$ NMR spectrum of $3 a\left(\mathrm{CD}_{3} \mathrm{CN}\right)$ over the temperature range $40-$ $76^{\circ} \mathrm{C}$, suggesting the $2 H$-pyran structure $3 a$ to be the favoured valence isomer under the conditions used for the hydride transfer reactions.

A mixture of equimolar amounts of 2,6diphenyl-4H-pyran (2c) and 2,6-diphenylpyrylium perchlorate (1c) in acetonitrile solution was recovered unchanged after keeping $3 \mathrm{~d}$ at $20^{\circ} \mathrm{C}$. However, boiling of the same mixture for $12 \mathrm{~h}$ yielded cinnamylidene acetophenone $(4 c)^{6}$ besides the pyrylium salt $1 c$. Hydride transfer from the $\gamma$-position of $2 c$ to the $\alpha$-position of $1 c$ leading to the regeneration of the latter and formation of the $2 H$-pyran $3 c$ which subsequently undergoes isomerisation to the dienone $4 c$, accounts for the observed products. In a similar reaction using 2,4,6triphenyl-4H-pyran $(2 d)$ and 2,4,6-triphenylpyrylium perchlorate (1d) no isomerisation could be detected at $20^{\circ} \mathrm{C}$. However, from the reaction mixture of the $4 H$-pyran $2 d$ and the pyrylium salt $1 d$ in boiling acetonitrile solution, besides the recovery of $1 d$, a crystalline compound of molecular formula $\mathrm{C}_{23} \mathrm{H}_{18} \mathrm{O}$ was isolated. The dienone structure $6 d$ was assigned to the latter compound for reasons which will be discussed below. The formation of $6 d$ must be the outcome of valence isomerisation of the initially formed $2 H$-pyran $3 d$ through $\gamma, \alpha$ hydride transfer.

The quantitative transformation of the $4 H$. pyrans $2 c$ and $2 d$ to the dienones $4 c$ and $6 d$, respectively, shows that the dienones are more stable than the $4 H$-pyrans as well as the $2 H$ pyrans $3 c$ and $3 d$. While in the case of the flavenes $2 a$ and $3 a$, the relative stabilities of the $4 H$-pyran, $2 H$-pyran and dienone structures could be assigned, such a relation could not be established for the $4 H$ - and $2 H$-pyrans (2c, $d$ and $3 c, d)$, since in the latter case the equilibrium between the pyrans is shifted to the more stable dienone forms.

Reduction of 2,6-diphenylpyrylium cation (1c) by means of sodium formate in boiling acetonitrile solution afforded, exclusively, the $4 H$-pyran $2 c$. The formation of the latter must be the outcome of a kinetically controlled for- mate reduction of $1 c$, since the $2 H$-pyran $3 c$ which may be concurrently formed, would be expected to isomerise to the dienone $4 c$ rather than to the $4 H$-pyran 2c. Reaction of 2,4,6-triphenylpyrylium perchlorate $(1 d)$ with sodium formate in boiling acetonitrile afforded the dienone $6 d$ in almost quantitative yield. The dienone $6 d$ must be formed through valence isomerisation of the $2 H$-pyran $3 d$. Under the conditions of the reaction, $3 d$ is expected to arise by two different routes, (i) hydride transfer from the formate anion to the $\alpha$-position of the pyrylium cation $1 d$ or (ii) isomerisation of the $4 H$-pyran $2 d$ formed via an attack of the hydride to the $\gamma$-position of $1 d$. In a trial to differentiate between these two possibilities, the reaction of the formate with $1 d$ was attempted at $20^{\circ} \mathrm{C}$, however, no reduction was observed.

The relation between the product distribution from the formate reduction of $1 a, 1 c$ and $1 d$ and the hydride acceptor ability of these cations will not be discussed in this work. However, it should be pointed out that the product distribution from hydride transfer to the flavylium cation $1 a$ was found to be greatly dependent on the nature of the hydride donor used. In the case of the formate anion as a hydride donor, the flavylium cation $1 a$ afforded a 1:1 mixture of the flavenes $2 a$ and $3 a .^{1}$ From a mixture of $1 a$ and the $4 H$-pyran $2 d$ in acetonitrile at $20^{\circ} \mathrm{C}$, the pyrylium salt $1 d$, and the flavenes $2 a$ and $3 a$ were obtained. In this reaction, in which the $4 H$-pyran $2 d$ acted as a hydride donor, the ratio between the flavenes $2 a$ and $3 a$ was found to be about 10:1 ( ${ }^{1} \mathrm{H}$ NMR). When the $4 H$-pyran $2 c$ was used as a hydride donor, the pyrylium salt $1 c$ and the flavene $2 a$ were isolated while the flavene $3 a$ could not be detected. These hydride transfer reactions are most likely kinetically controlled since they were carried out under conditions at which isomerisation of the flavene $3 a$ to $2 a$ catalysed by unreacted $1 a$ can be neglected.

The structural assignment of the dienone $6 d$ was based on its ${ }^{1} \mathrm{H}$ NMR spectrum which excludes the isomeric $2 H$-pyran form $3 d$. The spectrum exhibited two doublets at $\delta 8.57$ and 6.72 for two olefinic protons. The large vicinal coupling constant $(J 16.0 \mathrm{~Hz})$ is in complete agreement with the trans configuration of the $\gamma, \delta$ double bond $\left(\mathbf{R}^{2}=\mathbf{H}\right)$. The singlet at $\delta 6.95$

Acta Chem. Scand. B 30 (1976) No. 7 
was attributed to the proton in the $\alpha$ position $\left(\mathrm{R}^{4}=\mathrm{H}\right)$. The s-cis conformation was assigned to the enone single bond system. ${ }^{5}$ It seems likely that the low field chemical shift $(\delta 8.57)$ of one of the olefinic protons ( $\gamma$ or $\delta$ position) is related to the anisotropy effect exerted by the carbonyl group. Consequently, the cis configuration was assigned to the $\alpha, \beta$ double bond. The doublet at $\delta 8.57$ may either be attributed to the proton in the $\gamma$ position of $6 d$ or the proton in the $\delta$ position of $5 d$. However, preference for conformation $6 d$ can be given on basis of the similarity of its ${ }^{1} \mathrm{H}$ NMR and UV with that of 4-methyl-6-phenyl-3,5-hexadien2-one. The s-cis enone s-trans diene conformation $6 e$ has been assigned to the $\alpha, \beta$-cis $\delta, \gamma$ trans isomer of the latter dienone..$^{5}$

The probable temperature dependent $2 \mathrm{H}$ pyran/dienone equilibrium was examined by running the ${ }^{1} \mathrm{H}$ NMR spectrum of $6 d$ at -64 and $40^{\circ} \mathrm{C}$. However, no change in the spectrum was observed which indicates the stability of the dienone form $6 d$ over the above-mentioned temperature range. In this respect it should be pointed out that the 2,4,6-triphenyl-2Hpyran structure $(3 d)$ suggested by Dreux et al. ${ }^{\circ}$ for the product of reaction of 2-hydroxy-2,4,6triphenyl-2H-pyran and $\mathrm{KBH}_{4}$ seems unlikely. While no ${ }^{1} \mathrm{H}$ NMR data are given, its m.p., IR and UV are very close to those of the dienone $6 d$.

\section{EXPERIMENTAL}

The ${ }^{1} \mathrm{H}$ NMR spectra were recorded on a Varian A-60A instrument with TMS as internal standard. Infrared spectra were measured on a Perkin-Elmer 257 grating infrared spectrophotometer and ultraviolet spectra on a Cole. man Hitachi 124 double beam spectrophotometer. Mass spectra were recorded on an AEI MS902 instrument.

The methods of preparation, melting points and ${ }^{1} \mathrm{H}$ NMR data of 4-phenylflavylium perchlorate (1a), 4-phenylflav-2-ene (2a), 4-phenylflav-3-ene (3a), 3-deuterio-4-phenylflavylium perchlorate $(1 b)$ and 3-deuterio-4-phenylflav2 -ene $(2 b)$ are reported in an earlier publication. ${ }^{1}$ The pyrylium salts and $4 H$-pyrans used in this work are listed below with their most important physical data.

2,6.Diphenylpyrylium perchlorate (1c). ${ }^{7}$ Yellow needles, m.p. $230-231^{\circ} \mathrm{C}$ (acetic acid). ${ }^{\mathrm{H}} \mathrm{H}$ NMR spectrum (TFA): $\delta 8.97\left(J_{\mathrm{AB}} 8.6 \mathrm{~Hz}, \mathrm{l} \mathrm{H}\right.$, $\mathrm{AB}_{2}$-system $), 8.48\left(J_{\mathrm{AB}} 8.6 \mathrm{~Hz}, 2 \mathrm{H}, \mathrm{AB}_{2}\right.$ system), $8.1(10 \mathrm{H}, \mathrm{m})$.
2,4,6-Triphenylpyrylium perchlorate (Id). ${ }^{8}$ Yellow needles, m.p. $294-296^{\circ} \mathrm{C}$ (acetic acid). ${ }^{1} \mathrm{H}$ NMR spectrum (TFA): $\delta 8.57(2 \mathrm{H}, \mathrm{s})$, $8.0(15 \mathrm{H}, \mathrm{m})$.

2,6-Diphenyl-4H-pyran (2c). 2,6-Diphenylpyrylium perchlorate (1c) (1.5 g; $0.0045 \mathrm{~mol}$ ) was added in the course of $1 \mathrm{~h}$ to a stirred suspension of lithium aluminium hydride $(0.40 \mathrm{~g}, 0.011 \mathrm{~mol})$ in ether $(75 \mathrm{ml})$. After decomposition of excess lithium aluminium hydride, the ethereal solution was filtered and dried $\left(\mathrm{MgSO}_{4}\right)$. 2,6-Diphenyl-4H-pyran (2c) $(0.95 \mathrm{~g}, 95 \%$ yield) was obtained after evaporation of the ethereal solution as needles, m.p. $100-101{ }^{\circ} \mathrm{C} .{ }^{1} \mathrm{H}$ NMR spectrum $\left(\mathrm{CDCl}_{3}\right): \delta 3.03$ $(J 3.5 \mathrm{~Hz}, 2 \mathrm{H}, \mathrm{t}), 5.37(J 3.5 \mathrm{~Hz}, 2 \mathrm{H}, \mathrm{t})$, $7.5(10 \mathrm{H}, \mathrm{m})$.

It should be noted that the reported method ${ }^{\circ}$ for the synthesis of $2 c$ by reduction of $1 c$ with sodium borohydride in ether-water mixture gave a gummy product which required several recrystallisations.

2,4,6-Triphenyl-4H-pyran(2d). A much better yield of $2 d$ was obtained by a modification of the method reported by Dimroth et al. ${ }^{10}$ as follows: 2,6-Diphenylpyrylium perchlorate (1c) $(8.30 \mathrm{~g}, 0.025 \mathrm{~mol})$ was gradually added $(1 \mathrm{~h})$ to a stirred Grignard solution (from bromobenzene $(7.85 \mathrm{~g}, 0.050 \mathrm{~mol})$ and magne. sium $(1.83 \mathrm{~g}, 0.75 \mathrm{~mol})$ ) in ether $(175 \mathrm{ml})$. The reaction mixture was then poured into aqueous ammonium chloride solution and the ether layer was separated and dried $\left(\mathrm{MgSO}_{4}\right)$. The $4 H$-pyran $2 d(7.9 \mathrm{~g}, 90 \%$ yield $)$ was obtained after evaporation of the ethereal solution and crystallised in needles (ethanol), m.p. $111^{\circ} \mathrm{C}$. IR $\left(\mathrm{CHCl}_{3}\right): 1682,1640$ and $1600 \mathrm{~cm}^{-1} \cdot{ }^{1} \mathrm{H}$ NMR spectrum $\left(\mathrm{CDCl}_{3}\right): \delta 4.33$ $(J 4.0 \mathrm{~Hz}, 1 \mathrm{H}, \mathrm{t}), 5.47(J 4.0 \mathrm{~Hz}, 2 \mathrm{H}, \mathrm{d})$, $7.4(15 \mathrm{H}, \mathrm{m})$.

General method for the isomerisation reactions (Table 2). An equimolar amount of the reac-

Table 2. Isomerisation experiments.

Reactants Temp. Reaction Result period

$(1: 1) \quad\left({ }^{\circ} \mathrm{C}\right) \quad(\mathrm{h})$

\begin{tabular}{llrlll}
$2 a, 1 a$ & 20 & 72 & & Reactants $^{a}$ & \\
$2 a, 1 a$ & 80 & 15 & & Reactants $^{a}$ & \\
$2 a, 1 b$ & 20 & 2 & $2 a, 2 b, 1 a, 1 b$ & $(1: 1: 1: 1)$ \\
$2 b, 1 a$ & 20 & 2 & $2 a, 2 b, 1 a, 1 b$ & $(1: 1: 1: 1)$ \\
$3 a, 1 a$ & 20 & 72 & Reactants & \\
$3 a, 1 a$ & 80 & 15 & $2 a, 1 a$ & $(1: 1)$ \\
$3 a, 1 b$ & 20 & 72 & Reactants $a$ & \\
$3 a, 1 b$ & 80 & 15 & $2 a, 2 b, 1 a, 1 b$ & $(1: 1: 1: 1)$ \\
$2 c, 1 c$ & 20 & 72 & Reactants $a$ & \\
$2 c, 1 c$ & 80 & 12 & $4 c, 1 c$ & $(1: 1)$ \\
$2 d, 1 d$ & 20 & 72 & Reactants $a$ & \\
$2 d, 1 d$ & 80 & 12 & $6 d, 1 d$ & $(1: 1)$ \\
\hline
\end{tabular}

${ }^{a}$ Recovered unchanged.

Acta Chem. Scand. B 30 (1976) No. 7 
tants in acetonitrile solution was stirred at room temperature or refluxed as indicated in the table. The reaction mixtures were then treated with ether and the precipitated salts were filtered and identified by ${ }^{1} \mathrm{H}$. NMR data and melting point determination. The filtrates were evaporated and the residues were identified by ${ }^{1} \mathrm{H}$ NMR data. Whenever possible, crystallisation of the residues was attempted and the products were further characterised by their melting points. Compounds $2 a, 3 a, 2 c$ and $2 d$ were recovered unchanged after refluxing their solutions in acetonitrile for $15 \mathrm{~h}$.

1,3,5-Triphenylpenta-2,4-dienone (6d) (Table 2). This compound was obtained as pale yellow crystals (methanol), m.p. $125-126^{\circ} \mathrm{C}$. IR $\left(\mathrm{CHCl}_{3}\right): 1645,1610$ (weak), 1600 and $1580 \mathrm{~cm}^{-1}$. UV (ethanol), $\lambda_{\max }(\mathrm{nm}): 345(\varepsilon 24520$ ) and 268 ( $\varepsilon 15810)$. ${ }^{1} \mathrm{H}$ NMR spectrum $\left(\mathrm{CD}_{3} \mathrm{COCD}_{3}\right)$ : $\delta 6.72(J 16.0 \mathrm{~Hz}, 1 \mathrm{H}, \mathrm{d}), 8.57(J 16.0 \mathrm{~Hz}$, $1 \mathrm{H}, \mathrm{d}), 6.95$ (1 H, s), 7.7 (15 H, m). Molecular weight by MS: Found: 310.1353. Calc. for $\mathrm{C}_{23} \mathrm{H}_{18} \mathrm{O}$ : 310.1357 .

Reaction of 4-phenylflavylium perchlorate (1a) with sodium formate at room temperature. A solution of 4-phenylflavylium perchlorate (1a) $(0.50 \mathrm{~g}, 0.0013 \mathrm{~mol})$ in acetonitrile $(10 \mathrm{ml})$ was stirred with sodium formate $(0.40 \mathrm{~g}$, $0.006 \mathrm{~mol}$ ) overnight at $20^{\circ} \mathrm{C}$. Ether $(100 \mathrm{ml})$ was added and the precipitate was filtered. The residue $(0.15 \mathrm{~g}, 40 \%$ yield) obtained after evaporation of the filtrate was dissolved in deuteriochloroform. The ${ }^{1} \mathrm{H}$ NMR spectrum of this solution showed the characteristic signals of the $\mathrm{H}_{\beta}, \mathrm{H}_{\gamma}$ protons of 4-phenylflav-2-ene (2a) and the $\mathrm{H}_{\alpha}, \mathrm{H}_{\beta}$ protons of 4-phenylflav3-ene $(3 a)$, besides the aromatic protons signals. The integral ratio revealed a 1:1 ratio of the flavenes.

Reaction of 2,6-diphenylpyrylium perchlorate (Ic) with sodium formate. A solution of 2,6diphenylpyrylium perchlorate (1c) $(0.40 \mathrm{~g}$, $0.0012 \mathrm{~mol}$ ) in acetonitrile $(10 \mathrm{ml})$ was refluxed with sodium formate $(0.40 \mathrm{~g}, 0.006 \mathrm{~mol})$ for $5 \mathrm{~h}$. Ether $(100 \mathrm{ml})$ was added and the precipitate was filtered off. The filtrate after evaporation gave 2,6-diphenyl-4H-pyran (2c) $\left(0.25 \mathrm{~g}, 90 \%\right.$ yield), identified by ${ }^{1} \mathrm{H}$ NMR.

Reaction of 2,4,6-triphenylpyrylium perchlorate (1d) with sodium formate. A solution of $2,4,6$ triphenylpyrylium perchlorate $(1 d)(1 \mathrm{~g}, 0.0024$ mol) in acetonitrile (15 ml) was refluxed with sodium formate $(0.80 \mathrm{~g}, 0.012 \mathrm{~mol})$ for $10 \mathrm{~h}$. Ether $(150 \mathrm{ml})$ was added and the precipitate was filtered. The oily residue $(0.70 \mathrm{~g})$ after evaporation of the filtrate afforded the dienone $6 d(0.45 \mathrm{~g}, 60 \%$ yield $)$, m.p. $125-126^{\circ} \mathrm{C}$ on crystallisation from methanol.

When the above reaction was carried out at $20^{\circ} \mathrm{C}$ for $48 \mathrm{~h}$, the pyrylium salt $1 d$ was recovered unchanged.

Reaction of 4-phenylflavylium perchlorate (1a) with 2,4,6-triphenyl-4H-pyran (2d). A solution of 4-phenylflavylium perchlorate $(1 a)(0.25 \mathrm{~g}$, $0.0006 \mathrm{~mol}$ ) and 2,4,6-triphenyl-4H-pyran (2d)
$(0.20 \mathrm{~g}, 0.0006 \mathrm{~mol})$ in acetonitrile $(10 \mathrm{ml})$ was stirred at $20^{\circ} \mathrm{C}$ for $48 \mathrm{~h}$. Ether $(150 \mathrm{ml})$ was added and the precipitated 2,4,6-triphenylpyrylium perchlorate (1d) $(0.25 \mathrm{~g}, 95 \%$ yield), m.p. $294-296^{\circ} \mathrm{C}$ (acetic acid) was filtered. The crystalline residue after evaporation of the filtrate $(0.17 \mathrm{~g}, 95 \%$ yield) was identified by ${ }^{1} \mathrm{H}$ NMR to be a 10:1 mixture of 4-phenylflav-2-ene $(2 a)$ and 4-phenylflav-3-ene $(3 a)$.

Reaction of 4-phenylflavylium perchlorate (1a) with 2,6-diphenyl-4H-pyran (2c). A solution of 4-phenylflavylium perchlorate $(1 a)(0.30 \mathrm{~g}$, $0.0008 \mathrm{~mol}$ ) and 2,6-diphenyl-4H-pyran (2c) $(0.19 \mathrm{~g}, 0.0008 \mathrm{~mol})$ in acetonitrile $(10 \mathrm{ml})$ was stirred at $20^{\circ} \mathrm{C}$ for $48 \mathrm{~h}$. Ether $(150 \mathrm{ml})$ was added and the precipitated 2,6-diphenylpyrylium perchlorate $(1 c)(0.24 \mathrm{~g}, 90 \%$ yield), m.p$230-231^{\circ} \mathrm{C}$ (acetic acid) was filtered. 4-Phenylflav-2-ene (2a) $\left(0.21 \mathrm{~g}, 95 \%\right.$ yield), m.p. $109^{\circ} \mathrm{C}$ (ethanol) was obtained after evaporation of the filtrate and was further characterised by 1H NMR.

Acknowledgement. One of us (M.M. Mishrikey) is grateful to the Norwegian Agency for International Development (NORAD) for a fellowship.

\section{REFERENCES}

1. Mishrikey, M. M. and Østensen, E. T. Acta Chem. Scand. B30 (1976) 329.

2. Gosink, T. A. J. Org. Chem. 39 (1974) 1942.

3. Saalfrank, R. W. Tetrahedron Lett. (1974) 4509.

4. Duperrier, A. and Dreux, J. Tetrahedron Lett. (1970) 3127.

5. Kluge, A. F. and Lillya, C. P. J. Org. Chem. 36 (1971) 1977.

6. Griot, J.-P., Royer, J. and Dreux, J. Tetrahedron Lett. (1969) 2195.

7. Dimroth, K. and Wolf, K. H. Newer Methods of Preparative Organic Chemistry, Academic, New York 1964, Vol. 3, p. 409.

8. VanAllan, J. A. and Reynolds, G. A. J. Org. Chem. 33 (1968) 1102.

9. Whitlock, Jr., H. W. and Carlson, N. A. Tetrahedron 20 (1964) 2101.

10. Dimroth, K., Kinzebach, W. and Soyka, M. Chem. Ber. 99 (1966) 2351.

Received November 28, 1975.

Acta Chem. Scand. B 30 (1976) No. 7 